\title{
Madness, Suicide and the Victorian Asylum: Attempted Self-Murder in the Age of Non-Restraint
}

\author{
ANNE SHEPHERD and DAVID WRIGHT*
}

\section{Introduction}

On 20 July 1870, Catherine Tyrrell found herself transferred to another asylum. The 32-year-old nurse suffering from melancholia had previously been a private patient in Bethlem Hospital; but, having had her twelve months expire at that institution, ${ }^{1}$ she was conveyed across the metropolis and into the bucolic countryside and county asylum of Buckinghamshire. ${ }^{2} \mathrm{Up}$ to this point, Catherine had had a long and sad history of suicide attempts and food refusal. Indeed, when she was transferred the following year, this time from Buckinghamshire to the Surrey County Asylum at Wandsworth, she was listed as "very suicidally disposed". ${ }^{3}$ Now diagnosed as suffering from "mania", she managed only three months before arriving at her fourth institution in as many years - the Surrey County Asylum at Brookwood. On admission, the medical superintendent described, with transparent disapproval, the precautionary clothing that held her suicidal impulses in check:

She was brought in a canvas garment which fitted her person even down to her ankles, the arms however not going through the sleeves, but being folded across her chest close to her skin, the hands being locked in leather gloves. The jacket or whatever it is called being [fastened] at the back by 5 locks. All this complicated arrangement was immediately removed. There was no clothing of ordinary kind under it. ${ }^{4}$

\footnotetext{
* Anne Shepherd, MA, Dept. of History, Birkbeck College, University of London, Malet St, London WC1E 7HX. David Wright, DPhil, History of Medicine Unit, McMaster University, HSC 3N10-A, 1200 Main St W., Hamilton, L8N 3Z5, Canada.

The authors would like to thank the Wellcome Trust (History of Medicine Grants Panel) for grants in support of research upon which this article was based. We would also like to acknowledge the very helpful referees' comments made by Andrew Scull and Len Smith, the editorial assistance of William Bynum, and the contribution of attendees at seminars held at: St Patrick's Hospital, Dublin; University of Nottingham; McMaster University; and the Wellcome Centre for the History of Medicine, University College London.
}

\footnotetext{
'Bethlem Hospital normally allowed nonprivate or non-criminal lunatics to stay for a maximum of twelve months.

${ }^{2}$ Catherine had settlement in a Surrey Poor Law Union-St Saviour's-but was most likely transferred to Buckinghamshire due to overcrowding in the Surrey asylums. The Lunacy Commissioners allowed Poor Law Unions to make arrangements with magistrates from other counties in the event that there was no room in "their" county institution. For Catherine's admission notes to the Buckinghamshire Asylum, see the Buckinghamshire Record Office (BRO) AR $100 / 89 / 223$, pp. 324-5.

${ }^{3}$ Underlined in the original.

${ }^{4}$ Casebooks (Female) Brookwood Asylum, 1871, Surrey History Centre (SHC) Acc. 1523/3/ $21 / 2$.
} 
Dr Thomas Brushfield, the medical superintendent of the Brookwood Asylum, immediately took upon himself the task of unchaining Catherine from what he clearly considered apparel reminiscent of a pre-Conollyite era of mechanical restraint. In the first few weeks following her admission to Brookwood, he observed that Catherine had responded well to her new physical liberty, behaving placidly, and eating with a sharp knife. "She acts", he confided in his medical casebook, "without exhibiting any suicidal propensities at present." By early 1872, unfortunately, her behaviour deteriorated. Seemingly unprovoked bouts of aggression aimed at both fellow patients and attendants prompted the superintendent to administer morphine and chloral hydrate. Early in 1875, she attempted to strangle herself but appeared soon to recover and during the next six months her behaviour ranged from the diligent to the destructive before she was again transferred (back) to Wandsworth Asylum. Sadly, her persistent attempts to commit self-murder were ultimately successful. A short time after her arrival, she committed suicide by hanging. ${ }^{5}$

Catherine's tragic demise was not a singular incident. In 1882, the Lunacy Commission, the national inspectorate established in 1845 to supervise and regulate asylums in England and Wales, reported, as it always did, on asylum suicides for the previous year. During 1881, twenty-three patients had committed suicide in licensed institutions for the insane. Of these, most patients contrived to hang themselves with bedsheets, handkerchiefs tied together with bootlaces, or by "roller towels". Some patients fatally threw themselves down stairs, whilst others cut their throats with knives smuggled out of the scullery. Three of the twenty-three patients were out of the asylum when the self-murder had occurred. One patient escaped from Whittingham Asylum and lay down on the London and North Western Railway line, where he was found decapitated the next day. Two patients had been discharged on probation, seemingly recovered, only for one man to shoot himself in the head and the other to take an overdose of "chloral" . ${ }^{6}$ Suicide, and suicide attempts, it would seem, were a reality of the Victorian mental hospital.

This catalogue of deaths, selectively chosen for sensational effect, might easily reinforce the stereotype of the asylum as a locus of despair, desolation and death. But to interpret the deaths in this way would be misleading. According to Dr William Ogle, a contemporary physician and keen statistician of mortality in Victorian England, there were 42,630 suicides in England and Wales between 1858 and 1883, a mortality rate well in excess of 1,500 per year. ${ }^{7}$ By contrast, 265 individuals were reported to have "successfully" taken their own lives in asylums during the same twenty-five year period, a mortality rate that never exceeded 20 per year (Figure 1) ${ }^{8}$ The low figure, these Lunacy Commissioners concluded, must be attributed to the high levels of institutional "care and attention which [have been] bestowed on

\footnotetext{
${ }^{5}$ Ibid.

${ }^{6}$ Thirty-sixth report of the Commissioners in Lunacy, Parliamentary Papers (PP) [1882], vol. xxxii, pp. 89, 98-112, 199.

${ }^{7}$ William Ogle, 'Suicides in England and

Wales in relation to age, sex, season and
}

occupation', J. statist. Soc., 1886, 49: 101-35, p. 101.

${ }^{8}$ Tabulated from the annual reports from the Commissioners in Lunacy, 1859-1882. 


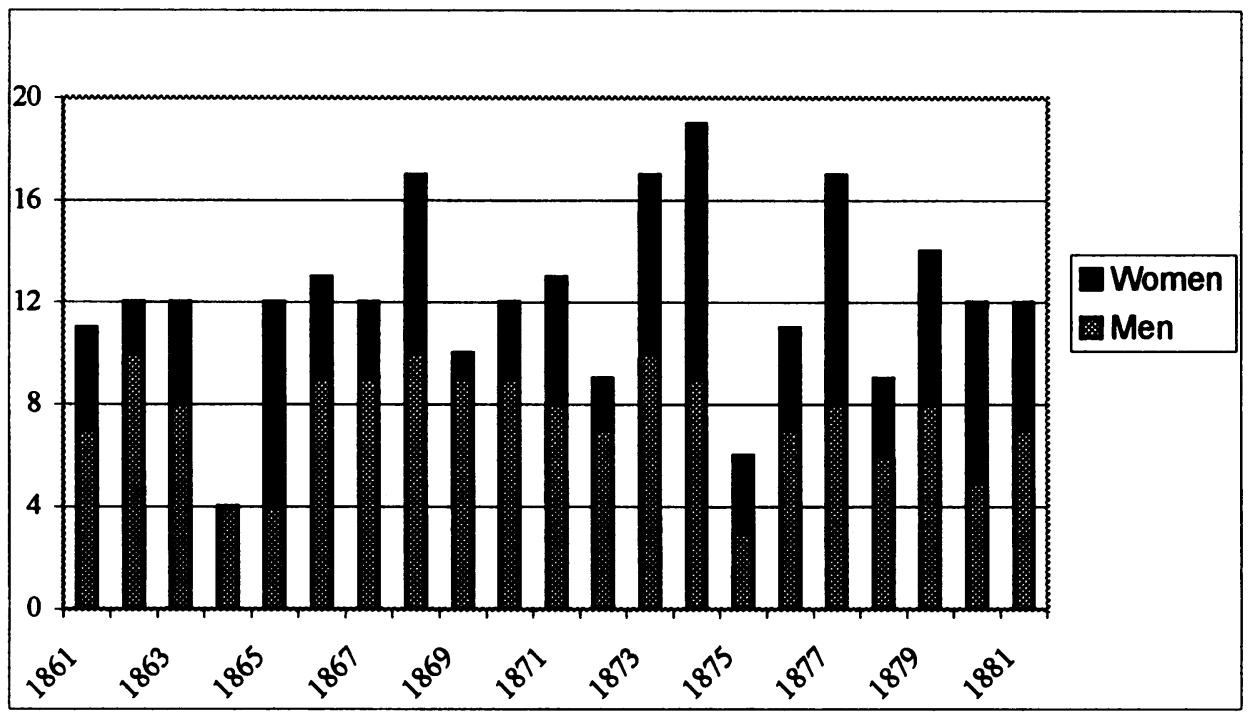

Figure 1: Reported suicides in licensed institutions for the insane, England and Wales, 1861-1881.

Source: Annual reports of the Commissioners in Lunacy, 1862-1882.

suicidal patients", 9 who ostensibly comprised one-quarter of all admissions. ${ }^{10}$ Others, however, were more circumspect in their conclusions. George Savage, himself an asylum medical superintendent, admitted that he did not believe that "more than five per cent" of admissions were "actively suicidal", which he defined as "patients who have made serious attempts on their lives, and [were] likely to repeat them"." Using his more restrictive definition, 650 admissions ( 5 per cent of 13,000 individuals admitted annually by 1881$)^{12}$ were "actively suicidal". Yet, even readjusting the numbers downward, the returns still suggest that fewer than 20 out of the 650 "actively suicidal" admissions successfully took their lives in institutions for the insane in 1881, compared with over 1,500 extramural suicides. Why was there such an apparent discrepancy between the fate of suicidal lunatics in the community and in asylums?

Few detailed studies of the history of suicide in England existed before the 1980s when a series of excellent publications rescued the subject from the periphery of social and medical history. Michael MacDonald and Terence Murphy demonstrated how suicide was secularized during the course of the early modern era. By the early nineteenth century, there had been a perceptible shift from suicide as predominantly

\footnotetext{
${ }^{9}$ Thirty-sixth report of the Commissioners in Lunacy, PP [1882], vol. xxxii.

${ }^{10} \mathrm{~W}$ Wynn Westcott, Suicide: its history, literature, jurisprudence, causation, and prevention, London, H K Lewis, 1885, p. 126; Ogle, op. cit., note 7 above, p. 115 .
}

${ }^{11} \mathrm{G}$ H Savage, 'Constant watching of suicidal cases', J. Mental Sci., 1884, 30: 17-19, p. 17.

${ }^{12}$ Derived from 1879 figures. See Fifty-fourth report of the Commissioners in Lunacy, PP [1900], vol. xxxvi, Appendix A, pp. 89, 95. 
a religious and legal concern, to one in which medical men began to play a prominent role. ${ }^{13}$ As Olive Anderson, in her monumental work on suicide in Victorian and Edwardian England, has illustrated, the reconfiguration of suicidality as a sign of mental "illness" served many social and professional ends. Medical superintendents of asylums, the forerunners to the psychiatric profession, saw a potentially important clientele through extending their territory to include those who attempted selfmurder. Alienists, as these medical men were commonly called, pressed for institutional treatment and control by asserting that suicide could be avoided if action were taken at an early enough stage of the illness. ${ }^{14}$ The medicalization of attempted or threatened suicide also constitutes a central theme in the work of Pat Jalland. By the early-Victorian period, as bourgeois values permeated the middle classes of society, suicide became inextricably linked with Victorian concerns with "bad deaths". The coroners' verdict of death by (suicidal) insanity, though involving the stigma of lunacy, at least guaranteed a Christian burial. ${ }^{15}$ Prior to 1832 , self-murderers were denied religious ceremony and consecrated ground, although many were discreetly placed in a separate part of the churchyard. ${ }^{16}$

One of the principal effects of research on the history of suicide in England ${ }^{17}$ has been to challenge one of Durkheim's famous dictums about the relationship between industrialization and self-murder. Durkheim postulated that suicide was rapidly increasing in modern society partly due to anomie, the demoralization and psychological dislocation fostered by rapid social change, urbanization and migration. ${ }^{18}$ His treatise reflected a widespread belief in the late nineteenth century that suicide, like insanity, was a price society was paying for a higher level of civilization. ${ }^{19}$ Olive Anderson, however, contended that there were no empirical data to conclude that suicide rates in Victorian England were higher in "industrial areas" than in "rural areas". ${ }^{20}$ Michael MacDonald analysed variations in suicide rates over the early modern period, including many areas as yet unaffected by the economic upheaval associated with industrial change. His data show an overall decline in suicide rates in the latter half of the eighteenth century, the very time when the industrial revolution was supposed to be taking off and a time when, he argues, the secularization of the

\footnotetext{
${ }^{13}$ Michael MacDonald and Terence $\mathbf{R}$ Murphy, Sleepless souls: suicide in early modern England, Oxford University Press, 1990.

${ }^{14}$ Olive Anderson, Suicide in Victorian and Edwardian England, Oxford University Press, 1987, esp. ch. 11.

${ }^{15}$ Pat Jalland, Death in the Victorian family, Oxford University Press, 1996, pp. 69, 70-1.

${ }^{16}$ Ibid. pp. $70-1$.

${ }^{17}$ This paper will look only at the historiography of suicide in England. For a discussion of the impact of Durkheim's ideas within American psychiatry, see Howard

Kushner, 'American psychiatry and the cause of suicide, 1844-1917', Bull. Hist. Med., 1986, 60: 36-57.

${ }^{18}$ This is not to argue that Durkeim considered only anomic suicide. See, inter alia,
}

\author{
Jack Douglas, The social meanings of suicide, \\ Princeton University Press, 1967. \\ ${ }^{19}$ Emile Durkheim, Le Suicide: étude de \\ sociologie, Paris, F Alcan, 1897. This view was \\ first put forward by Henry Morselli, whose \\ groundbreaking work on the statistics of suicide \\ influenced the French theoretician. For a \\ discussion of Morselli's belief that suicide was a \\ result of the Darwinian struggle of advanced \\ societies, see Barbara Gates, 'Suicide and the \\ Victorian physicians', J. Hist. behav. Sci., 1980, \\ 16: $164-74$, pp. 169-71. \\ ${ }^{20}$ Olive Anderson, 'Did suicide increase with \\ industrialisation in Victorian England?', Past and \\ Present, 1980, 86: 149-73.
}


act of self-murder made authorities more willing to report suicides accurately. ${ }^{21}$ Similarly, Victor Bailey, in his excellent case study of Victorian Hull, believes that Durkheim's basic dictums need to be "substantially modified" in any empirical study of suicide. $^{22}$

Bailey's recent contribution to the historiography of suicide continues a dominant and influential tradition of researching the history of self-murder from death certificates, coroners' reports, and official parliamentary statistics. We thus know a great deal about those who were "successful", but much less about the social responses to those who had "failed" to take their own lives. Attempted self-murder remains relatively uncharted territory. ${ }^{23}$ Within the history of psychiatry, case studies of asylums have alluded to individual suicidal patients confined in private licensed homes, charitable lunatic hospitals, and county and borough asylums (see below), and recent work on the history of clinical psychiatry has outlined the conceptual relationship between suicidal intention and the classification of insanity, ${ }^{24}$ but there have been, as yet, no histories specifically devoted to how asylums responded to suicidality. This article investigates the identification, incarceration and treatment of "suicidal lunatics" in Victorian England.

First it will provide an overview of the asylum system, outlining the process of certification and the context of committal. As the article will show, attempted suicide, and the threat of suicide, were important criteria in the determination and classification of insanity and the decision of families, communities, workhouse officials and local medical practitioners to seek institutional confinement. The second part of the article will examine the characteristics of certified lunatics who were incarcerated in the county asylums of Surrey and Buckinghamshire in the twenty years leading up to the social investigations into suicide in the mid-1880s. As excerpts from admission papers will illustrate, suicidality included a range of behaviours and intentions, from the description of individuals who had clearly attempted self-murder to depressed patients who expressed an often imprecise "wish to die". Lastly, this article will investigate the surveillance of suicidal patients within the walls of the pauper asylums. As the "lunacy reform movement" campaigned for the abolition of mechanical restraint (used to control the violent behaviour of asylum inmates), asylum doctors instructed staff to adopt a range of strategic measures to prevent suicides within the institutions. These measures included suicide surveillance, protective clothing, force-feeding and, increasingly, drugs. Indeed, with the near prohibition on mechanical restraint and the dramatic explosion in the number of institutional patients, medical staff relied on the use of sedatives and narcotics to control those at risk of killing themselves, ushering in an increasing reliance on pharmacological interventions.

\footnotetext{
${ }^{21}$ Michael MacDonald, 'The secularization of suicide in England, 1660-1800', Past and Present, 1986, 111: $50-100$.

${ }^{22}$ Victor Bailey, "This rash act": suicide across the life cycle in the Victorian city, Stanford University Press, 1998, ch. 1.

${ }^{23}$ The exception being Anderson, op. cit., note 14 above, ch. 7 .
}

\footnotetext{
${ }^{24}$ See chapters by German Berrios and Michael MacDonald, in German Berrios and Roy Porter (eds), A history of clinical psychiatry: the origin and history of psychiatric disorders, London, Athlone, 1996, pp. 612-32.
} 


\section{Anne Shepherd and David Wright}

This comparative study of two institutions will be based largely on the detailed examination of records of patients admitted to county asylums in the nineteenth century, including certificates of insanity, reception orders, admission registers, casebooks, discharge and death registers. The nineteenth century witnessed a revolution in the documentation of madness, a process of surveillance that provides unparalleled sources for a social history of attempted suicide. This paper will explore, in particular, the certificates of insanity, admission registers and casebooks for patients admitted to the second Surrey County Asylum (Brookwood) and the Buckinghamshire Asylum near Aylesbury. Data on the socio-demographic characteristics of patients were analysed by a relational database and supplemented by qualitative extracts from medical casebooks. These sources provide a unique view on the history of suicide and a counterbalance to the coroners' reports utilized by most historians of suicide.

\section{Suicide and the Asylum in Nineteenth-Century England}

Under the 1808 Asylums (Wynn's) Act, Parliament empowered committees of county magistrates to establish rate-aided asylums for their insane poor. ${ }^{25}$ Definitions of who should be confined were vague, and usually revolved around the local magistrates agreeing with Poor Law Overseers that the individual was "insane" and a "fit person to be taken under care and control". ${ }^{26}$ The lexicon of the early nineteenth-century legislation placed great emphasis on the adjectives "violent" and "dangerous", placing these asylums in an older Georgian tradition of controlling vagrancy and public displays of disorder. ${ }^{27}$ Because of sensitivity over the alleged incarceration of "sane" individuals for pecuniary gain, ${ }^{28}$ legislation regulating institutions mandated that "private" (i.e. paying) patients be certified by medical practitioners who had no connection with the receiving institution. Certificates of Insanity included brief descriptions of aberrant behaviour, strange delusions, unusual excitement or "depressed spirits". Between 1811 and 1828, Parliament extended the requirements over certification to include also pauper patients sent to county asylums. ${ }^{29}$ Under this unfolding system of legal checks and balances, a second admission document, the Reception Order, was required for all admissions. Reception Orders required that a local parish clergymen or magistrate complete a profile of the patient at the time of admission signed by the parish or Poor Law union clerk. ${ }^{30}$ The "Statement of Particulars" of the Reception Orders listed the inmate's age, sex, marital status, past history, and other social and medical characteristics. It also

\footnotetext{
${ }^{25}$ This article will not address directly the question of suicidal criminal lunatics, suicidal Chancery lunatics, or suicidal individuals committed to private licensed homes.

${ }^{26}$ David Wright, 'The certification of insanity in nineteenth-century England', Hist. Psychiatry, 1998, 9: 267-90, pp. 271-7.

${ }^{27}$ Roy Porter, Mind-forg'd manacles: a history of madness in England from the Restoration to the Regency, London, Athlone, 1987, pp. 117-18.
} 


\section{Madness, Suicide and the Victorian Asylum}

asked explicitly whether the patient was "suicidal". Thus from the earliest years of the English asylum system, a determination had to be made on every patient as to the likelihood of their committing self-murder.

The inclusion of "whether suicidal" in the Reception Orders was a recognition of the self-harm to which contemporaries saw the mad to be vulnerable. Such knowledge had come from hard-learned experience. Throughout the first half of the nineteenth century, asylums received many patients who had recently attempted self-murder or who had threatened to do so. William Parry-Jones, for instance, illustrates that it was not uncommon for private madhouse keepers at the turn of the nineteenth century to accept suicidal lunatics sent by parishes and families. ${ }^{31}$ Similarly, Anne Digby, in her monograph on the voluntary Quaker York Retreat, acknowledges that straitjackets were commonly employed in the 1820 s in cases where patients were in danger of killing themselves. ${ }^{32}$ As Poor Law officers conveyed more and more individuals to formal medical institutions, they and asylum medical superintendents were becoming familiar with the dangers posed by suicidal lunatics. By 1845 , the year Parliament extended and expanded the provisions of the 1808 County Asylums Act, Poor Law officials and local medical practitioners had become experienced in responding to problems posed by suicidal insanity.

The two asylums under study reflect this intersection of institutional medical practice and suicide surveillance and control. By the early 1850 s, the Buckinghamshire magistrates were still making provision for their pauper lunatics in Poor Law Union workhouses, and in various extra-county institutions, such as the Northampton Asylum, and the Littlemore Asylum outside Oxford. Only after continued pressure from the national inspectorate - the Lunacy Commission - did the county magistrates finally adhere to the 1845 Asylums Act and build an asylum in 1853 in the parish of Stone, just outside the county capital of Aylesbury. ${ }^{33}$ The institution was constructed for 100 men and 100 women; ${ }^{34}$ however, like many asylums at mid-century, the demand outstripped supply as the patient population reached 400 by 1870 . Surrey opened its second county asylum (Brookwood) on 17 June 1867, under the auspices of the Metropolitan Asylums Board, the newly created authority charged with the care of the infectious and insane poor of Greater London. Conveniently located three miles from Woking Station, Brookwood's intention was to relieve the overburdened Surrey County Asylum at Wandsworth, built in 1841. Described in the Lancet as appearing like "a cheery hamlet of almshouses", ${ }^{35}$ Brookwood stood on an elevated site of 150 acres of rural land, and initially housed 650 inmates,

\footnotetext{
${ }^{31}$ William Llewellyn Parry-Jones, The trade in lunacy: a study of private madhouses in England in the eighteenth and nineteenth centuries, London, Routledge and Kegan Paul, 1972, p. 115, and Table 36 , p. 218 , for statistics on suicidal admissions to two private madhouses in the 1840 s.

${ }^{32}$ Anne Digby, Madness, morality and medicine: a study of the York Retreat, 1796-1914, Cambridge University Press, 1985, pp. 79-80. See also Leonard D Smith, Cure, comfort and safe custody: public lunatic asylums in early nineteenth-
}

century England, London, Leicester University Press, 1999, pp. 250-7.

${ }^{33}$ For a history of the institution, see John Crammer, Asylum history: Buckinghamshire County Pauper Lunatic Asylum-St. John's, London, Gaskell, Royal College of Psychiatrists, 1990.

${ }^{34}$ Eighth report of the Commissioners in Lunacy, PP [1854], vol. xxix, p. 69.

35 'Report of the Lancet Commission on lunatic asylums: Brookwood Asylum', Lancet, 4 December, 1875 , ii: 816-20, p. 817. 


\section{Anne Shepherd and David Wright}

but such was the demand for accommodation that ambitious extension plans commenced almost immediately, with an additional 57 acres of farmland purchased by 1880 .

The Brookwood and Buckinghamshire asylums drew their patient populations from different social and geographical backgrounds. Up to the $1880 \mathrm{~s}$, many of Brookwood's patients originated from the workhouses of poor south London areas such as Bermondsey, Camberwell, Rotherhithe, Lambeth and Southwark. Prior to its opening, many mentally ill paupers were detained in workhouse accommodation or in licensed private asylums. The rural location of Brookwood offered a therapeutic environment; its very distance from the metropolis provided the recommended isolation from family and friends, and the extensive grounds allowed for sufficient outdoor employment and exercise. In the mid 1870s, 25 per cent of all cases sent from workhouses were either epileptic or syphilitic, and the majority of all cases were described as "dangerous". Occupations included labourers, bricklayers, carpenters, dressmakers, laundresses and domestic servants. The Buckinghamshire patients constituted a wider socio-economic constituency, partly due to the absence of private asylums in the county. ${ }^{36}$ Patients spanning the adult life course were admitted to the asylum from all Poor Law Unions of this overwhelmingly rural county. Their occupational backgrounds reflected the employment of the lower two-thirds of Buckinghamshire society, including large numbers of agricultural workers, female domestic servants and women and men employed in the cottage industries of lacemaking and strawplaiting. As the only asylum in the county, the institution outside Aylesbury appears to have admitted a greater percentage of the middling classes than Brookwood, for in the Metropolis prosperous families had greater opportunities for securing philanthropic or private care. The two pauper asylums thus represent, in general terms, two typical asylums in the Victorian era: the general provincial asylum of Buckinghamshire, and Brookwood, the more specialized ancillary pauper institution, serving a more chronic inmate population. ${ }^{37}$

\section{Suicidal Admissions to Brookwood and Buckinghamshire Asylums}

Quantitative research on patient populations in nineteenth-century Britain has changed dramatically our understanding of the Victorian asylum. Recent research has revealed that patients spanned the adult life course; that they were confined predominantly, though not exclusively, from households and sent by relatives; that by age, gender and occupation, they reflected the communities from whence they came; and, lastly, that there were short-term as well as medium-term and long-term

\footnotetext{
${ }^{36}$ Buckinghamshire had no licensed homes for private patients until 1867 , when a small institution, Winslow Hall, began accepting between six and ten patients annually.

${ }^{37}$ For a detailed study of the Brookwood Asylum, see Anne Shepherd, 'The public and
}

private institutionalisation of the insane in late nineteenth-century Surrey: class and gender at Brookwood Asylum and Holloway Sanatorium', forthcoming doctoral thesis, Birkbeck College, University of London. 


\section{Madness, Suicide and the Victorian Asylum}

patients. Short lengths of stay reflected the quick discharge of many patients and also a high mortality rate. ${ }^{38}$ Results from the analysis of records from these two asylums conform, more or less, to these general findings. In Buckinghamshire, there were 941 women and 886 men admitted to the asylum between the years 1863 and 1875, a sex-ratio that reflected that of the adult population of the county at that time. An equal number of individuals died in the institution as were discharged, and the median length of stay for both groups was between 12 and 15 months. The data for Brookwood show that between its opening in 1867 and $1891,7,191$ patients were admitted, and that the sex-ratio, as in Buckinghamshire, reflected that of the county as a whole. ${ }^{39}$ Two-thirds of inmates were not resident for longer than five years; however, any chance of recovery after that period rapidly diminished. Patients appear to have suffered from more serious (physical) illnesses than the Buckinghamshire patients. High mortality rates were even reflected in the younger patients: up to a third of admissions under the age of 35 died within five years of entering the asylum. The poor recovery rates and high death rates were frequently attributed by the medical superintendent to the failing health of those patients originating from the South London workhouses and institutions.

An analysis of data from the admission registers of both asylums reveals the problem suicide "risk" posed to medical superintendents. In Buckinghamshire, 17 per cent of male first admissions and 22 per cent of female first admissions were classified as suicidal. In Brookwood, the rates were higher, approaching one-third of all patients. Figure 2 illustrates the difference between the reported rates of the two institutions by gender and age-group. Three findings immediately stand out. First, the rates were much higher in Brookwood, the institution receiving a greater proportion of patients through urban, densely populated Poor Law Union workhouses. Second, women were returned with higher rates of suicidality than their male counterparts of the same institution (even though men were more successful in completed suicide). ${ }^{40}$ Third, there was a general trend to higher rates of suicidality in older age groups, peaking in the age-class of 50-59, and then declining slightly.

The 1845 Lunatics Act required that all patients confined in licensed institutions had to be certified as insane before their confinement. ${ }^{41}$ After 1853, these certificates included lay as well as medical descriptions of disordered behaviour and symptoms. Inscriptions were most often transcribed directly into the medical

\footnotetext{
${ }^{38}$ For a recent volume of research on confinement, see Joseph Melling and Bill Forsythe (eds), Insanity, institutions and society, 1800-1914: a social history of madness in comparative perspective, London, Routledge, 1999.

${ }^{39}$ As in Buckinghamshire, 53 per cent of Brookwood's admissions were women, the same proportion as women in the adult population.

${ }^{40}$ Bailey, in a study of the local press of Hull, Yorkshire, found a female:male ratio of 2:1 in
}

attempted suicides. Bailey, op. cit., note 22 above, p. 129. He also found that men "successfully completed" suicide more often than women in the decades, 1841-1899, and that the rate of suicide rose with the age cohort (for both sexes). See ibid., pp. 132-9, Tables 6.2-6.4.

${ }^{41}$ An emergency provision permitted the incarceration of an individual without a certificate, but required three certificates to be completed within three days of admission. 


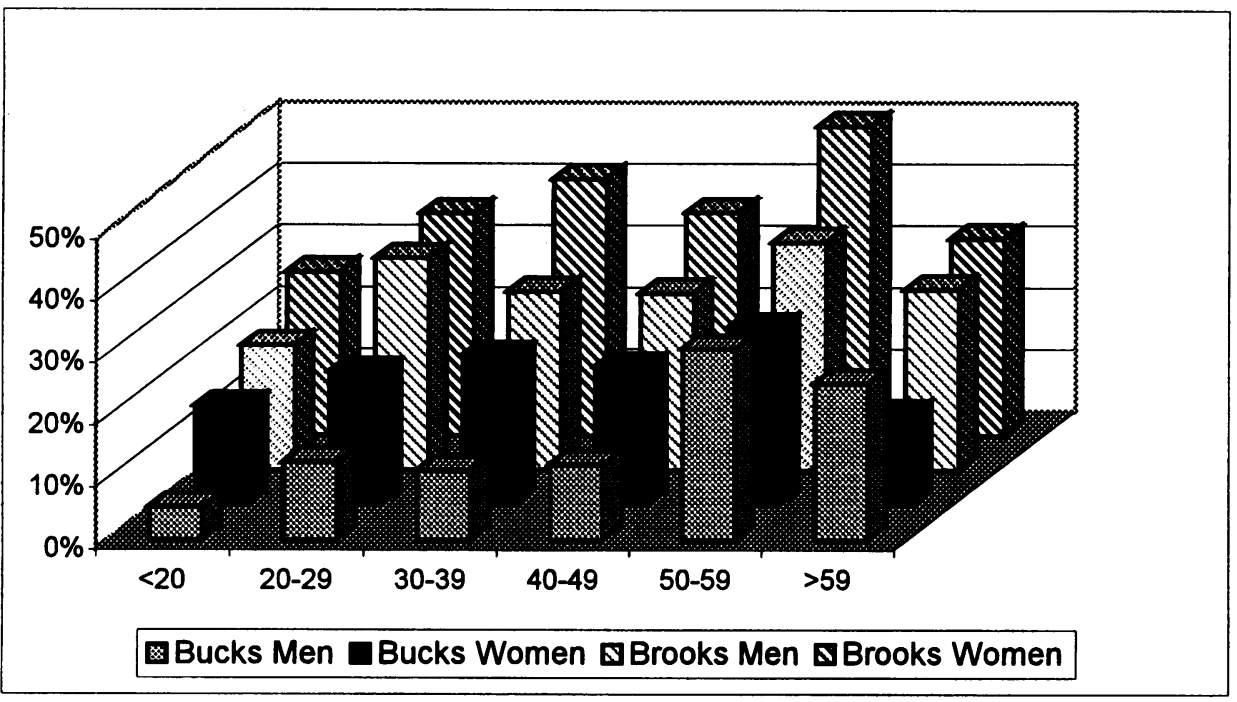

Figure 2: Proportion of patients labelled suicidal, by sex and age, Buckinghamshire and Brookwood asylums, selected years, 1853-1881. Number of patients: Brookwood (424); Buckinghamshire (1591).

Sources: Brookwood Admission Registers, SHC Acc. 1523/3/1-4; Medical Registers of Admissions, St John's Hospital (Buckinghamshire Asylum), Buckinghamshire County Record Office (BRO), AR 100/89/ 49-53; Alphabetical List of Patients, St John's Hospital, BRO AR 100/89/64-65; Medical Register of Discharges and Deaths, St John's Hospital, BRO AR 100/89/69-71.

casebooks, injecting lay observations of suicidal behaviour into "medical" documents. These brief, but often vivid descriptions humanize the bare statistics listed in Figure 2 and illustrate the different roads to the asylum. As mentioned earlier, the most common route to licensed institutions was directly from households in which the patient was living. In these cases, household members petitioned local Poor Law officials and magistrates to permit the confinement of the suicidal person in the asylum. The husband of Mary Ann Wilkins, for instance, sent a letter accompanying her admission to Brookwood on 13 May 1878 , setting out her circumstances, which he hoped would be of assistance. He detailed their diminishing social position due to his business losses over twenty years, Mary Ann's "severe attacks" of rheumatic fever and bronchitis and her eventual dependency on drink, so that:

... her manner has been quite at variance with her natural quiet disposition, and on the evening of the 8th instant she appeared depressed, but I did not apprehend that her mind was deranged, but during the brief period of two minutes while I left the room, she cut her throat with a table knife which lay on the supper table $\ldots{ }^{42}$

\footnotetext{
${ }^{42}$ Brookwood Casebook (Females), SHC Acc. $1523 / 3 / 21 / 6$.
} 


\section{Madness, Suicide and the Victorian Asylum}

Mary Ann had attempted suicide on a previous occasion, when she was not taken into custody, but her stay was short at Brookwood and she was discharged as recovered on 3 July of the same year. Joseph Stratford was a fifty-year-old Buckinghamshire sawyer, whose census schedule reveals that he was married with three children remaining in his household - two daughters who were lacemakers, aged fourteen and twenty, and a son who was an apprentice sawyer, aged eighteen. Stratford's case is particularly poignant. He was disabled in an accident and was no longer able to ply his trade. Immediately prior to confinement, he had grown depressed, "moping" about his household and sitting for hours on his bed "muttering to himself". After four months of his melancholic and erratic state, and one or two instances of his running out of his house in a desperate and wild manner, his wife found a pair of scissors hidden under their bed. She finally called in the Poor Law relieving officer who agreed to have Joseph sent to the asylum. He was certified and admitted to the county asylum on 1 August 1861. In the asylum, attendants were required to force feed Stratford who continued to "creep" about the institution in despair and depression. After six years, he had not improved and his wife petitioned for his discharge (which she was allowed to do under the Lunacy Laws). Yet Stratford refused to leave the asylum until several petitions from his wife persuaded the county Visiting Committee to forcibly remove him back to Hughenden. These are but two cases of hundreds whereby families sought asylum control and participated in the confinement of household members, if only on a short-term basis.

Recent scholarship on the Devon County and Leicestershire County lunatic asylums has documented the important role the Poor Law played in the identification and conveyance of patients to county institutions. The workhouse, it seems, was often used as a secure place of surveillance before the individual could be transported to the county institution. ${ }^{43}$ This alternate route to the asylum was evident in the descriptions of the recent histories of suicidal patients admitted to the Surrey and Buckinghamshire institutions. Take, for example, the brief workhouse stay of a troubled patient admitted to the Brookwood Asylum:

The patient first threw himself under the wheels of a cab, and was run over and most severely bruised; he then sat down on a fire; next he jumped from a three storey window; he tried to strangle himself with a sheet; he swallowed a bottleful of soap and opium liniment; finally, after his removal to the workhouse, he inflicted a severe wound in his throat, and in this condition he was received into the asylum.

Remarkably, he was later discharged from Brookwood recovered. ${ }^{44}$ Transporting suicidal lunatics to the asylum was no easier for the Poor Law authorities of the county of Buckinghamshire. John Donnelly was a gentleman's servant "who

\footnotetext{
${ }^{43}$ Bill Forsythe, Joseph Melling and Richard Adair, 'The New Poor Law and the county pauper lunatic asylum - the Devon experience 1834-1884', Soc. Hist. Med., 1996, 9: 335-55, and Peter Bartlett, The Poor Law of lunacy: the
}

administration of pauper lunatics in mid-nineteenth century England, London, Leicester University Press, 1999.

${ }^{44} \mathrm{~T}$ N Brushfield, 'On medical certificates of insanity', Lancet, 1880, i: 711-13, p. 712. 


\section{Anne Shepherd and David Wright}

had lately taken to drinking". The arresting constable testified that Donnelly had "got out of the train at Leighton Buzzard \& thr[ew] himself into the canal", when he was being transported to the asylum he even attempted "to jump out of the railway carriage". ${ }^{45}$ Sarah Montague had displayed a variety of bizarre behaviours in her own household in Tring, Buckinghamshire. Singing, dancing, refusing food and suffering from hallucinations, she was conveyed to her local workhouse for safe custody. The master of the Union House stated that "she is constantly looking upwards \& imagining a man at the window threatening her with [a] pistol, also she says that her parents are dead, when they have recently visited her". Her occasional violence was sufficient to have her transferred to the county asylum. ${ }^{46}$

Contemporary statistics on the method of completed suicide reflect many of the means of attempted self-murder described in the asylum medical casebooks and certificates of insanity. Writing in 1885, Wynn Westcott, Deputy Coroner for Central Middlesex, compiled and published data on the rates and methods, by sex, for suicide in his own jurisdiction. The same year, William Ogle presented a paper to the Royal Statistical Society on mortality and occupation in England and Wales, part of which was devoted to suicide mortality. Both men and women, they concluded, had four principal means of killing themselves: hanging, cutting and stabbing, drowning and poisoning. But the patterns of reported suicide showed that women "preferred" drowning and poisoning. Men, by contrast, took their own lives more frequently by hanging themselves. The second most popular method for men was cutting their own throats, "a practise", Westcott averred, "strongly favoured in England and Ireland, but rarely found to be so elsewhere". ${ }^{47}$ Although it is impossible to provide definitive evidence, the asylums' admission records and contemporary accounts of completed suicides give the impression that women did tend to attempt suicide using less violent means, such as drowning or poisoning. ${ }^{48} \mathrm{Men}$, by contrast, attempted suicide less often, but when they did, they used more violent means, such as gun-shots and cutting their own throats, and were more successful. The most common method, however, for completed self-murder and attempted self-murder seems to have been hanging, and it was one which posed a constant danger to underresourced asylum medical superintendents.

\footnotetext{
${ }^{45}$ Medical Casebooks (Males),

Buckinghamshire Asylum, BRO AR 100/89/218, pp. $103-4$

${ }^{46}$ Case notes of Sarah Montague, Medical Casebooks (Females) Buckinghamshire Asylum, BRO AR 100/89/224.

${ }^{47}$ Westcott, op. cit., note 10 above, pp. 145-6.

${ }^{48}$ Poisoning was apparently a very popular method in England and the United States, and not surprisingly, opium, morphia and their
}

\begin{abstract}
preparations were the most frequently used, as well-known poisons, rather than an overdose of safe drugs. Other easily procured poisons in use were prussic acid, cyanide of potassium (used for photographic purposes), carbolic acid and derivatives used for disinfecting, essential oil of bitter almonds (cookery), and anti-vermin preparations such as strychnine. Westcott, ibid., p. 146 .
\end{abstract}




\section{Madness, Suicide and the Victorian Asylum}

Table 1

Method of suicides in England and Wales, c.1881, as calculated by two contemporary observers.

\begin{tabular}{lrrrrr}
\hline & \multicolumn{2}{c}{ Males } & & \multicolumn{2}{c}{ Females } \\
\cline { 2 - 3 } \cline { 5 - 6 } Means & Ogle & Westcott & & Ogle & Westcott \\
\hline Hanging & $41.7 \%$ & $34.3 \%$ & & $24.0 \%$ & $23.1 \%$ \\
Cut throat* & $20.7 \%$ & $18.6 \%$ & & $12.9 \%$ & $11.6 \%$ \\
Drowning & $15.2 \%$ & $17.5 \%$ & & $26.4 \%$ & $35.2 \%$ \\
Poison & $7.9 \%$ & $9.0 \%$ & & $14.5 \%$ & $19.2 \%$ \\
Fire-arms & $6.7 \%$ & $8.2 \%$ & & $1.0 \%$ & $0.6 \%$ \\
All other causes & $7.3 \%$ & $12.4 \%$ & & $21.2 \%$ & $10.2 \%$ \\
\hline
\end{tabular}

Other causes (Westcott): rail/vehicles, strangling, falls from height, cuts and stabs, burns, scalds and explosions, and suffocation by vapours. Adapted from Wynn Westcott's combined estimates for suicides in 1881 and 1882. W Wynn Westcott, Suicide: its history, literature, jurisprudence, causation, and prevention, London, H K Lewis, 1885, p. 147.

*Ogle included cuts and stabs with the "cut throat" group. William Ogle, 'Suicides in England and Wales in relation to age, sex, season and occupation, J. Statist. Soc., p.118, Table ix.

\section{Suicide and Nineteenth-Century Psychiatry}

Medical historians have documented well the dramatic growth in the number of asylums during the Victorian era. ${ }^{49}$ This social phenomenon provided the foundation for the formation and consolidation of a medical speciality based on individuals charged with administering mental hospitals. Commonly known as asylum medical superintendents, alienists, or medico-psychologists, these medical men began to claim expertise in the treatment of insanity. The care and treatment of the insane had not always been a medical prerogative, and much debate ensued in the early nineteenth century over the alleged efficacy of the medical approach. ${ }^{50}$ However, the medical profession eventually succeeded in securing a monopoly over the formal treatment of the insane through the 1845 Asylums Act, which stipulated that all public asylums in England and Wales had to be run by a qualified medical practitioner. The men who acceded to the post of asylum superintendent consolidated their position by publishing treatises on insanity, forming professional associations to promote their common interests, and establishing a journal for the dissemination of articles to

\footnotetext{
${ }^{49}$ Peter McCandless, “"Build! Build!” The controversy over the care of the chronically insane in England, 1855-1870', Bull. Hist. Med., 1979, 53: 553-74.

${ }^{50}$ William F Bynum, 'Rationales for therapy in British psychiatry, 1780-1835', in Andrew Scull
}

(ed.), Madhouses, mad-doctors and madmen: the social history of psychiatry in the Victorian era, Philadelphia, University of Pennsylvania Press, 1981 , p. $35-57$. 


\section{Anne Shepherd and David Wright}

cultivate a body of expert knowledge. By the mid-Victorian period, the British psychiatric profession had been born. ${ }^{51}$

The principal medical treatises on insanity published during this period of professional formation examined several aspects of attempted self-murder, including debates over the pathogenesis of suicidal impulses, the identification of those most at risk, the appropriate locus of treatment, and the necessity of timely intervention. John Haslam, writing in the earliest years of the century, considered isolation from family and household as being vital for the wellbeing of all patients, particularly those suffering from melancholia. It was crucial, he contended, to separate the mad person from the environment that engendered or exacerbated suicidal propensities. ${ }^{52}$ Forbes Winslow, in The anatomy of suicide, attributed suicide almost exclusively to insanity, and, in particular, depression. ${ }^{53} \mathrm{John}$ Conolly, the doyen of Victorian alienists, wrote of the dangers of overlooking the potentially suicidal until it was too late. Like Haslam, Conolly urged early intervention and institutional treatment. ${ }^{54}$ John Bucknill and William Tuke, authors of the standard Victorian textbook on psychological medicine, extended Conolly's view that attempted suicide occurred in specific situations in which the "suicidal impulse" overcame rational control. Importantly, they associated suicidality with three states of unsound mind: "monomania", where the patient was inclined to self-destruction; "melancholia", where the individual was driven to despair; and "delusional [states]", when the sufferer heard a voice commanding him or her to act on its behest. ${ }^{55}$

Alienists of lesser fame also speculated on the classification of suicidality. Brookwood's first medical superintendent, Dr Thomas Brushfield, observed amongst his patients those whom he described as having no obvious suicidal motive, yet persistently placed their lives in peril. He also identified patients who, as a result of their illness, were self-consciously and reflectively determined to end their own lives. Both groups posed a serious threat, especially those depressed in mind:

... I would urge upon all medical practitioners the necessity of regarding all cases of melancholia as having a suicidal tendency, whether or not there have been threats or attempts indicating it; the depressing nature of the symptoms, if it does not manifest itself at first, always tends to develop it. The medical man should make the relatives understand this, especially if they are averse to sending the patient away from home to be treated. ${ }^{56}$

Indeed, Brushfield was emphatic that every case of melancholia had the potential for suicidal action. The second group, he felt, was exemplified by those who do not wish to eat, whether or not this is due to "complete indifference, from the idea that it is poisoned, from the belief that it has been obtained by depriving others, etc.". ${ }^{57}$ Brushfield's analysis reflected the fact that even relatively unimportant

\footnotetext{
${ }^{51}$ For a classic account of the rise of the psychiatric profession in the nineteenth century, see Andrew Scull, The most solitary of afflictions: madness and society in Britain, 1700-1900, New Haven and London, Yale University Press, 1993.

52 John Haslam, Observations on madness and melancholy, London, J Callow, 1809, pp. 308-9.

${ }^{53}$ Gates, op. cit., note 19 above, pp. $165-6$.
}

\footnotetext{
${ }^{54} \mathrm{John}$ Conolly, An inquiry concerning the indications of insanity, London, $\mathbf{J}$ Taylor, 1830, pp. 256-7.

${ }^{55}$ John Bucknill and Daniel Tuke, Psychological medicine, as quoted in Westcott, op. cit., note 10 above, p. 121.

${ }^{56}$ Brushfield, op. cit., note 44 above, p. 712.

${ }^{57}$ Ibid.
} 


\section{Madness, Suicide and the Victorian Asylum}

county medical superintendents had developed an expertise in identifying those at risk.

The observations of alienists thus derived first and foremost from their institutional experience. Hallucinations recorded in the certificates of insanity and medical casebooks often included patients hearing voices commanding individuals to kill themselves; paranoid delusions of people "out to get them" or "wanting them dead", also drove some patients to conceive of suicide as a pre-emptive act. The desperation with which some patients tried to kill themselves could be challenging and, no doubt, profoundly disturbing to staff. James Walding, a patient of Buckinghamshire, had threatened to hang himself, believing that he was going to be hanged by his enemies. Within the asylum he refused food and had to be force fed. One month after admission, he attempted suicide by tying his neck-tie to the door. After the attendants intervened he "beg[ged] to be shot" ${ }^{58}$ Other delusions manifested the nihilism of individuals who thought that their "life was lost" and/or "that [they were] going to die". Very common, particularly amongst female patients, was the delusion that all food was poisoned, thus leading to food refusal and self-starvation. These features occurred in a range of combinations and varying degrees of duration and severity. As medical superintendents of institutions containing several hundred patients, Brushfield and John Humphrey (the medical superintendent of the Buckinghamshire Asylum) were well-placed to observe suicidal admissions, and their broad generalizations reflect the composition of patients admitted to the institutions under study. Clearly, Humphrey associated disorders of mood with suicidal inclinations. A crosstabulation of suicidality and his diagnosis of 1,600 patients (Figure 3) demonstrates a marked correlation between suicidality and the two states associated with depressed mood-mania with depression and melancholia.

It is clear, therefore, that Victorian alienists had begun to formulate an approach to the identification and confinement of suicidal lunatics. For instance, they identified a severe depression in spirits to be a dangerous correlate of suicidality. They also recognized that auditory hallucinations and delusions of persecution were often "willing" the individual to self-murder. As a pre-emptive act, medical superintendents urged early intervention in institutions under medical control, where proper surveillance could be carried out. This paper will now turn to the intervention within the walls of the asylum.

\section{Treatment and Surveillance of Suicidal Lunatics}

Brushfield and Humphreys operated in an era, and a profession, still influenced by the debate over the abolition of mechanical restraint. The unshackling of patients represented, to progressive medical practitioners, the symbolic victory of enlightened scientific humanitarianism over the barbarism of neglect and idleness. The apochryphal story of Philippe Pinel unchaining the inmates at the Salpêtrière hospital in

\footnotetext{
${ }^{58}$ Case notes for James Walding, Medical Casebooks (Males), Buckinghamshire Asylum, BRO AR 100/89/218, p. 394.
} 


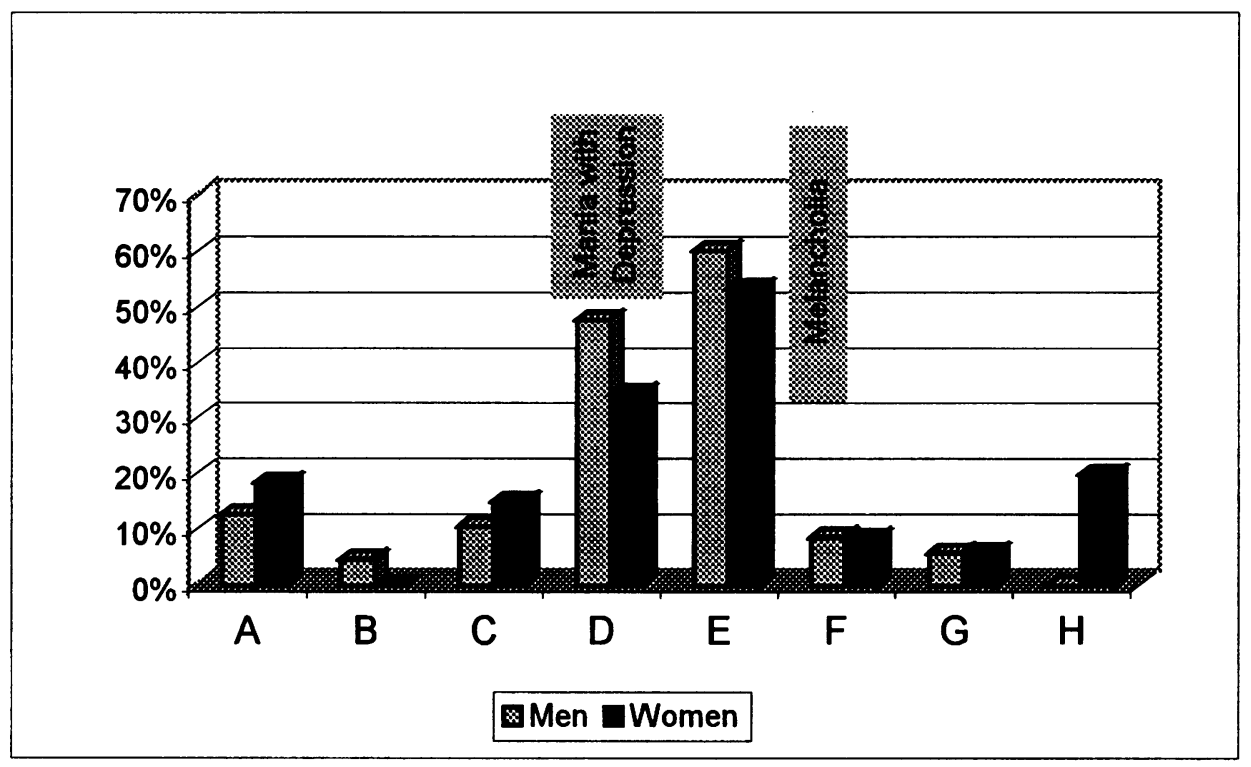

Figure 3: Proportion of patients labelled suicidal by diagnosis, Buckinghamshire Asylum, 1853-1872 $(\mathrm{n}=1,591)$.

Legend: A-Ordinary Mania; B-General Paralysis of the Insane; C-Other Manias; DMania with Depression; E-Melancholia; F-Dementia; G-Idiocy/Imbecility; H-Other

Sources: Medical Registers of Admissions, St John's Hospital (Buckinghamshire Asylum), Buckinghamshire County Record Office (BRO), AR 100/89/49-53; Alphabetical List of Patients, St John's Hospital, BRO AR 100/89/64-65; Medical Register of Discharges and Deaths, St John's Hospital, BRO AR 100/89/69-71.

Paris took on mythical status. Within England, the advocacy of "non-restraint" grew slowly from a series of tragedies, including the chaining and neglect of patients at the York subscription asylum, and the famous discovery and depiction of William Norris in Bethlem Hospital. Non-restraint was allegedly first implemented in public asylums by the resident surgeon of the Lincoln subscription asylum, Robert Gardner Hill ${ }^{59}$ but it was John Conolly who appropriated the mantle of the champion of non-restraint at the Middlesex Asylum (Hanwell), one of the largest asylums in the world at mid-century. ${ }^{60}$ Mechanical restraint was considered at odds with the prevailing, if vague ideology of treating the insane in a humane manner, commonly known as "moral treatment". Most famously associated with the Quaker York Retreat, moral treatment believed in individual self-restraint and moral (that is,

\footnotetext{
${ }^{59}$ Leonard D Smith, 'The "great experiment": the place of Lincoln in the history of psychiatry', Lincolnshire History and Archaeology, 1995, 30: $55-62$, p. 55.

${ }^{60}$ Andrew Scull, 'John Conolly: a Victorian psychiatric career', in idem, Social order/mental
}

disorder: Anglo-American psychiatry in historical perspective, London, Routledge, 1989, pp. $162-212$. 


\section{Madness, Suicide and the Victorian Asylum}

psychological) therapy. Unchaining lunatics became the physical symbol of this new and enlightened form of therapeutic endeavour. ${ }^{61}$

Andrew Scull has illustrated how the ideal of moral treatment was compromised by the dramatic growth of these institutions during the latter half of the nineteenth century. With the substantial increase in the average capacity of institutions-from 200 patients in the 1830 s to 800 in the 1880 s-daily therapeutic interactions were removed from superintendents and transferred to the asylum attendants. Burgeoning patient populations thus represented a challenge to institutions subscribing, officially at least, to the policy of non-restraint. ${ }^{62}$ Simultaneously, the Lunacy Commissioners adopted a stricter surveillance over the internal actions of asylum staff, regulating attendants' behaviour, urging the dismissal of staff for neglect and mistreatment, and obliging medical superintendents to complete more and more paperwork on the treatment of patients, including the number of times mechanical restraint was used in any given year. Further, the 1862 Lunatics Amendment Act stipulated that all deaths in asylums were to be reported to the local coroner and to the Lunacy Commissioners. ${ }^{63}$ All suicides and suspicious deaths were then to be fully investigated. The Lunacy Commissioners acted on the principle of naming and shaming institutions that had failed in their professional duty to prevent suicides from occurring. Completed suicides became a sign of moral failure on the part of medical superintendents and the cause for intense public scrutiny of individual institutions. Medical superintendents were thus placed in a precarious position. A burgeoning inmate population and increasing patient:staff ratio made the regulation and control of violent and dangerous inmates more and more difficult; yet the regulating authority insisted on the abolition of mechanical restraint, one of the tried-and-tested means of preventing self-harm and aggression. This dilemma was acutely felt in the control of suicidal admissions.

So how did asylums cope with suicidal patients in the context of the dramatic growth in numbers of patients and the professional prohibition on mechanical restraint? Evidence reveals that several strategies were employed. First, suicidal admissions were assigned to specifically equipped rooms, with bed linen made of non-tearable material. Medical superintendents issued "caution notices" to alert attendants to the identity of patients at risk, and night attendants were instructed to check on the patients at regular intervals (often once an hour). During the day, a close watch was kept on patients at risk; they were not allowed to use any sharp objects or to wander out of doors alone. The constant shadowing of patients was recognized as imperfect, an invasion of privacy, and not necessarily of benefit to all "suicidal" patients. As George Savage, co-editor of the Journal of Mental Science, commented after years of observing suicidal inmates: "Patients have repeatedly told me that when constantly watched they felt as if they were being dared to do a thing, and naturally set themselves to evade their tormentors. A perfect attendant does not

\footnotetext{
${ }^{61}$ Akihito Suzuki, 'The politics and ideology of non-restraint: the case of the Hanwell Asylum', Med. Hist., 1995, 39: 1-17.
}

\footnotetext{
${ }^{62}$ Andrew Scull, Museums of madness: the social organization of insanity in nineteenth-century England, London, Penguin, 1979, ch. 6.

${ }^{63} 25$ \& 26 Vict. c. 111 , s.44.
} 


\section{Anne Shepherd and David Wright}

irritate a patient perhaps, but I have not found one yet." 64 Although the forcefeeding of patients, by spoon, nasal tube or stomach pump, was not a rare occurrence, preventive measures, constant surveillance and speedy response were more common forms of institutional intervention.

The culture of prevention nevertheless revolved around the diligence of the asylum staff. As Westcott observed: "nothing but a constant and lynx-eyed survey will prevent the self-destruction of a large proportion of lunatics, when they have a wave of suicidal tendency passing over their minds". ${ }^{65}$ The ability of attendants to discharge their duty, however, must have been compromised by the burgeoning size of the inmate population and, thus, the patient to staff ratio. At Brookwood, with an average of 10.5 male patients per attendant and 12.6 female patients per attendant, errors were bound to occur. There were frequent attempts at self-destruction where patients were outwitted by the more sharp eyed attendants. The comparatively liberal regime endorsed at nearby Holloway Sanatorium, a managed institution for the insane middle-classes in the county of Surrey, was not initially so successful. ${ }^{66}$ Partly as a result of the lack of human resources, the medical casebooks reveal that the medical superintendents of Brookwood and Buckinghamshire consistently employed medicines to sedate suicidal cases; the length of the treatment was often dependent on the early achievement of quietness and manageability, as the cost of medicines were a constraint on overuse. Opium, chloral hydrate, bromide of potassium and digitalis are frequently referred to in the case notes, used on an alternating basis in pursuit of the desired result. More unusually, bromide of ammonium and Indian hemp were also administered, as in the case of James Larkin, a very noisy and allegedly suicidal patient admitted to Brookwood in 1871 . He appeared to benefit from this combination to "very soothing effect" when opium failed to quieten his noisiness and foul language. ${ }^{67}$ The general impression from the sources is that drugs were widely used during this period. Purgatives, shower-baths and the application of blisters to various parts of the body were also frequently employed, usually in conjunction with drug treatment. The superintendent of the Buckinghamshire Asylum was particularly concerned with the temperature of the heads of suicidal maniacs, and occasionally, reflecting a longstanding belief in the value of hydrotherapy, prescribed cold showers to calm some suicidal patients. ${ }^{68}$

Carolyn Hart, 26 years old, a hawker, arrived at Brookwood in June 1871, suffering from suicidal mania. She provides a good illustration of how the asylum used virtually every means at its disposal to manage a demanding patient. During her four-year stay, she attempted suicide five times, and on the sixth, secreted a knife that was given up before any further attempt was made. She was noisy, abusive to

\footnotetext{
${ }^{64}$ Savage, op. cit., note 11 above, p. 19.

${ }^{65}$ Westcott, op. cit., note 10 above, p. 128.

${ }^{66}$ Holloway suffered the acute embarrassment of having two patients (one male and one female) commit suicide on the same day in March 1887, necessitating a public enquiry at which the hospital was exonerated from negligence, the coroner noting in his summing up that lunatics "were very cunning in their methods of making
}

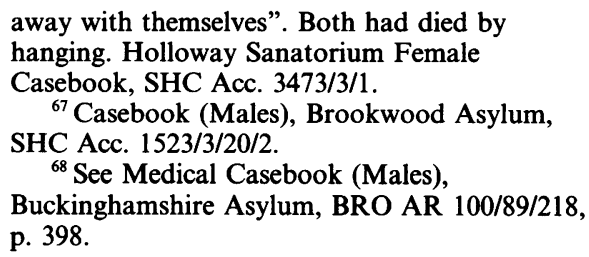


the attendants, destructive, obscene, foul-mouthed, and "filthy". Opium, digitalis, bromide of ammonium with Indian hemp, and cannabis, were all tried with various, though usually short-lived, degrees of success. She was so badly behaved that orders were given to shave her head as a punishment, yet despite this and the application of blisters to the back of the neck, her mania continued virtually unabated, and further suicide attempts occurred, including setting fire to her own dress. Despite the avowed dislike of mechanical restraint, there were occasions, such as in Carolyn's case, where a strong dress or jacket was used for a day or two at a time. ${ }^{69}$ After being on the receiving end of the full gamut of institutional strategies, she was discharged in May of 1875 as recovered.

\section{Conclusions}

During the course of the nineteenth century, between one-quarter and one-third of all admissions to lunatic asylums were described in their admission papers as "suicidal" even though "dangerousness" (either to self or others) was not a criterion for confinement required by English law. Such a reported prevalence of "suicidality" amongst asylum admissions shows a similarity to the results of research on other countries. ${ }^{70}$ During the mid-Victorian period, families, police, clergy, local medical practitioners and Poor Law officials acted individually, or in concert, to confine individuals as a preventive measure in response to acts of self-violence or the threats of individuals to do so. To what extent this preventive measure was "successful" implies that the historian can have a firm grasp of how many individuals would have been likely to kill themselves were it not for the intervention of the authorities and the careful surveillance of asylum staff. This is, perhaps, an unanswerable question. Asylum records, however, provide a unique source with which to investigate the identification and medical treatment of suicidal behaviour and a useful comparison to the more frequently used coroners' reports that underpin most historical reconstructions of research on Victorian suicide.

Our research confirms the view, first put forward by Olive Anderson that, although patients were commonly described as suicidal in admission records, suicides within the walls of the asylum were rare and becoming less common. ${ }^{71}$ Part of the apparent success had to do with the emergence of refined preventive measures. Earlier in the century, restraint was commonly used - either in the form of straitjackets or manacles. But in the wake of the lunacy reform movement, which attacked mechanical restraint, medical superintendents were obliged to employ other means to prevent suicides within their institutions. During the period under question, strict surveillance and the frequent use of sedatives, became more commonly employed. ${ }^{72}$ Penalties—such

\footnotetext{
${ }^{69}$ Casebooks (Females), Brookwood Asylum, SHC Acc. 1523/3/21/2.

${ }^{70}$ Mark Finnane, Insanity and the insane in post-famine Ireland, London, Croom Helm, 1981, p. 151.

${ }^{71}$ Anderson, op. cit., note 14 above. The overall impression, at least from official statistics, is that the proportion of asylum deaths by suicide
}

declined sharply in the last third of the nineteenth century, from 0.63 per cent in 1867 to 0.14 per cent in 1911. Ibid., p. 403.

${ }^{72}$ See Digby, op. cit., note 32 above, p. 198. This is not to imply that the use of drugs was uncommon prior to the advent of non-restraint in English asylums. See Smith, op. cit., note 32 above. 


\section{Anne Shepherd and David Wright}

as fines and dismissal-for attendants on duty during a suicide, coupled with the publicity and coroner's report resulting from a "successful" suicide, made medical superintendents and staff eager to avoid such occurrences within the walls of the asylum.

One area that remains to be researched is the prevalence of suicide amongst discharged, formerly "suicidal" patients. Under the Victorian lunacy laws, friends and relatives could demand the discharge of patients from institutions. Further, the medical superintendent had the legal responsibility to discharge a patient who appeared to be recovered. The absence of a desire to commit suicide was a central determinant in the decision of medical superintendents to recommend to county magistrates the discharge of patients back to the community. Despite this, a few cases illustrate that some patients took the opportunity of their new-found freedom to kill themselves. David Stovell, for instance, a married agricultural labourer from Worplesdon, in Surrey, was admitted to Brookwood in 1876 suffering from mania with general paralysis. He was classified as suicidal. Once admitted, he was considered manageable, although after three weeks he tried to escape without success. By September he was settled, quiet, rational and employed, to the extent that he was conditionally discharged on the 16 February 1877 . One month's probation was successfully completed, he was discharged as "recovered" only to commit suicide by drowning on 28 March. The verdict of the enquiry was "Suicide while of unsound mind". ${ }^{73}$ Brookwood was not alone in this tragedy. Charlotte MacKenzie illustrates how two patients discharged from the private Ticehurst asylum killed themselves, one by throwing himself into the sea, the other by leaping out of a window. ${ }^{74}$ Victor Bailey mentions that some of the suicides in his case study of Hull were indeed former patients of the local asylum, discharged not on the recommendation of the medical superintendents, but at the request of relatives "who wanted them out". Record linkage between county coroners' reports and asylum discharge records might reveal the consequences of discharge for the suicidal.

It is clear that the entry "suicidal" on the admission orders of patients included a wide range of behaviours and clinical features. Indeed, some Victorian commentators, such as Savage, believed that the "true" rate of suicidality was closer to 5 per cent of asylum admissions than the 20-30 per cent reflected in the asylum admission registers. In the ongoing negotiation between workhouse authorities and asylum superintendents, one can speculate that Poor Law officials might have, in some cases, exaggerated the danger of suicide in order to secure access to a dwindling resource of beds. The evidence from the admissions records of Brookwood, Surrey's second county asylum, shows that the majority of patients admitted between 1867 and 1881 came from the workhouses of South London, so that the term "suicidal", which appears in the majority of summary casebook information, must be viewed with a degree of contextual sensitivity. Such terminology, along with the label "dangerous", could have been used to provide

\footnotetext{
${ }^{73}$ Casebooks (Males), Brookwood Asylum, SHC Acc. 1523/3/20/4.

${ }^{74}$ As quoted in Charlotte Mackenzie, Psychiatry for the rich: a history of Ticehurst
}

Private Asylum, 1792-1917, London, Routledge, 1992, p. 179.

${ }^{75}$ Bailey, op. cit., note 22 above, p. 56. 


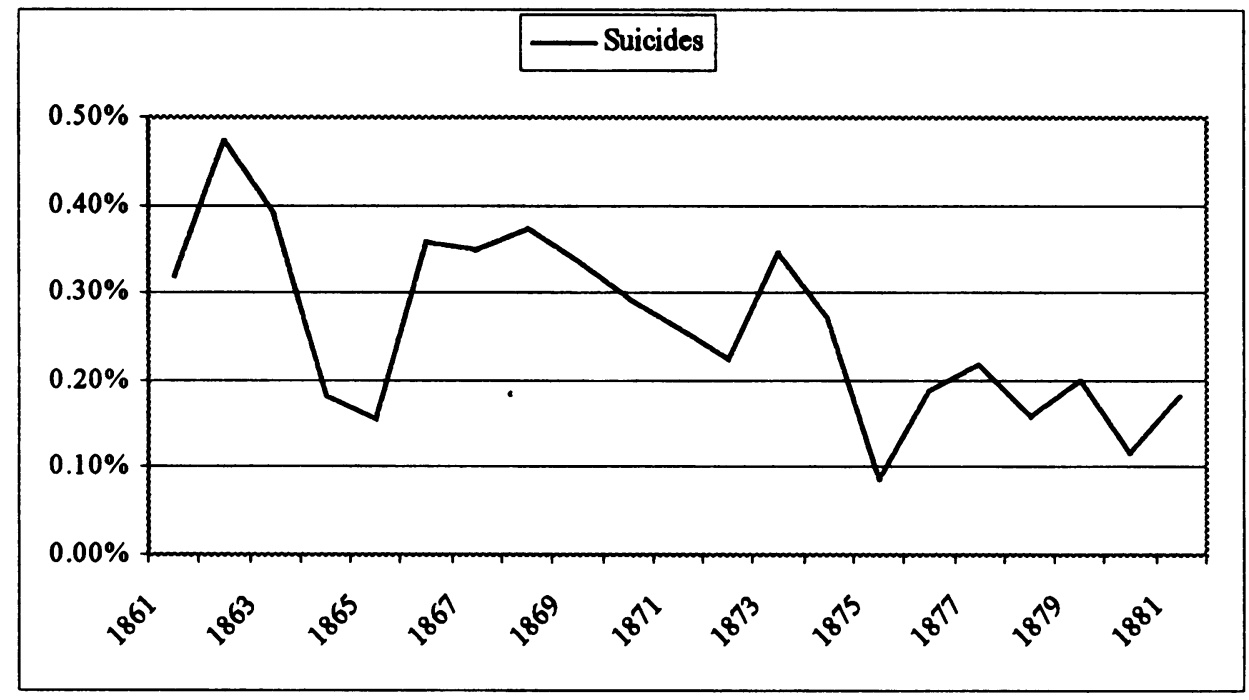

Figure 4: Proportion of asylum deaths listed as suicides, England and Wales, 1861-1881.

Source: Annual reports of the Commissioners in Lunacy, 1862-1882.

the workhouse authorities with the rationale to transfer their more difficult patients to the county asylum. Once incarcerated, many suicidal patients did not demonstrate such tendencies, and nor indeed were the extra precautions so often recommended in contemporary medical publications carried out. The fact that the apparent rate of suicidality in admissions to private asylums appears to have been much lower-between 10 per cent and 15 per cent-also provides circumstantial evidence to support this contention. ${ }^{76}$

Despite the increasing importance of the formal medical institution as a locus of control, there were many households which chose to forego institutional confinement, whether for economic, social or cultural reasons. There was a proportion of households who, when faced with insane and suicidal relatives, refused to countenance admission to an asylum, even though, in a strictly calculative way, this was in their own financial interest. ${ }^{77}$ District visitors who suggested that suicidal relatives be taken to asylums were sometimes met with stiff resistance. ${ }^{78}$ Thus, just as many patients who were labelled "suicidal" in asylum admission documents were not "actively" suicidal, so too were there many suicidal individuals in the community

${ }^{76}$ This contention is supported by comparative statistics for middle-class asylums. Preliminary research from the Holloway Sanatorium reveals that fewer patients were described as suicidal. Anne Shepherd, forthcoming doctoral thesis. Likewise, returns from the Lancaster Asylum, a pauper asylum, in the early 1840 s revealed a much lower rate of suicidality- 12.5 per cent for men and 14.5 per cent for women.

${ }^{77}$ Bailey, op. cit., note 22 above pp. $54-5$.

${ }^{78}$ George Behlmer, Friends of the family: the English home and its guardians, 1850-1940, Stanford University Press, 1998. 


\section{Anne Shepherd and David Wright}

who remained outside the purview of alienists. More research is required on those suicidal individuals who stayed outside the reach of institutional psychiatry before a comprehensive picture can be drawn of the role of asylums in suicide prevention during the Victorian era. 